\title{
Retracted: Research on Intelligent Function Design of Vocational Education System under Mobile Learning Mode
}

\author{
Journal of Mathematics
}

Received 25 November 2022; Accepted 25 November 2022; Published 27 December 2022

Copyright $\odot 2022$ Journal of Mathematics. This is an open access article distributed under the Creative Commons Attribution License, which permits unrestricted use, distribution, and reproduction in any medium, provided the original work is properly cited.

Journal of Mathematics has retracted the article titled "Research on Intelligent Function Design of Vocational Education System under Mobile Learning Mode" [1] due to concerns that the peer review process has been compromised.

Following an investigation conducted by the Hindawi Research Integrity team [2], significant concerns were identified with the peer reviewers assigned to this article; the investigation has concluded that the peer review process was compromised. We therefore can no longer trust the peer review process, and the article is being retracted with the agreement of the Chief Editor.

\section{References}

[1] L. Qing, "Research on Intelligent Function Design of Vocational Education System under Mobile Learning Mode," Journal of Mathematics, vol. 2022, Article ID 9684363, 10 pages, 2022.

[2] L. Ferguson, "Advancing Research Integrity Collaboratively and with Vigour,” 2022, https://www.hindawi.com/post/advancingresearch-integrity-collaboratively-and-vigour/. 


\title{
Research on Intelligent Function Design of Vocational Education System under Mobile Learning Mode
}

\author{
Li Qing \\ School of Preschool and Art Education, Xinyang Vocational and Technical College, 464000 Xinyang, China \\ Correspondence should be addressed to Li Qing; liqing@xyvtc.edu.cn
}

Received 28 November 2021; Revised 17 December 2021; Accepted 21 December 2021; Published 19 January 2022

Academic Editor: Lazim Abdullah

Copyright @ 2022 Li Qing. This is an open access article distributed under the Creative Commons Attribution License, which permits unrestricted use, distribution, and reproduction in any medium, provided the original work is properly cited.

\begin{abstract}
Because the traditional vocational education system has intelligent functions, long running time, and low recommendation accuracy of vocational education resources, the vocational education system under mobile learning mode is designed. The system is designed through the registration and login function module, course learning function module, examination and evaluation function module, communication and interaction function module, mobile learning function module, and personalized recommendation function module. In the personalized recommendation function module, the user's preference for vocational education resources is obtained by calculating the user's interest weight, as well as personalized recommendation of vocational education resources. The simulation results show that the intelligent function of vocational education system can operate normally under the designed mobile learning mode, the operation efficiency is high, and the effect of Vocational Education Resource Recommendation is good.
\end{abstract}

\section{Introduction}

Despite the fact that vocational education is at the forefront of the nation, innovative classroom reform concepts have played a significant role in its growth. There are still many problems in the cultivation of modern vocational education, particularly secondary vocational education, and the only digital campus network or public network information transmission network courses used in teaching, particularly micro courses, are few and far from meeting the needs [1]. The content of network resources is unappealing, and the building of network resources is inadequate [2]. Network and teaching informatization have received insufficient attention; teaching information resources are organized in their own way; there are no unified norms; teaching information is difficult to share; it cannot adapt to current information technology developments; and it has not been fully applied to classroom teaching. In actuality, the cost of utilizing different kinds of public websites is too expensive, making use uncomfortable; information professionalism is lacking, making use low and inconvenient. Various vocational education application support systems have a poor overall impact, low quality, and inconsistent after-sales service [3]. The use of mobile learning technology, combined with students' own characteristics, and the use of mobile phones, PDA, and other mobile learning terminals can not only obtain the required learning courses. Therefore, it is of great practical significance and practical value to design vocational education system under mobile learning mode and study its intelligent function [4].

Literature [5] designs the vocational education and teaching assistance system based on WeChat public platform. Firstly, the overall architecture of vocational education and teaching assistance system, the system hardware and software under the overall architecture, and the system hardware through PC and server are designed, and then the PC is integrated into WeChat public platform to design the system software function modules, including database and WeChat public platform. According to the system hardware and software design, the design of vocational education teaching assistant system is realized. Finally, the simulation experiment shows that the designed system has good functionality. Literature [6] designs a vocational education auxiliary teaching system based on data mining. The system designs the overall architecture of vocational education auxiliary teaching system through three-tier B/S structure and designs the system 
functional structure according to the system architecture, including acquisition function module, storage function module, processing function module, analysis function module, and mining function module. However, the intelligent functions of the above two systems run for a long time, resulting in low system operation efficiency. Literature [7] used the Python framework to create the general structure of a distant teaching aid system for vocational education, as well as the system function modules, which included acquisition, preprocessing, recognition, and query. To obtain student face images, the obtained student face images are preprocessed, the student face images are captured and aligned, and OpenCV technology was used. Facial feature information was extracted and recognized to determine the students' status, and the results were sent to the front end for teachers to view. Teachers may use the query module to look up students' previous learning status to use as a reference for increasing the quality of vocational education. Through the map browsing module, point recording module, data query module, coefficient calculation module, weather viewing module, route preview module, and occurrence survey, literature [8] designed the field geology teaching assistant system on the Android studio platform and verified the overall performance of the system through multiple iterative experiments, in order to lay a good foundation for students' academic performance. However, the above two systems have low accuracy in recommending educational resources, resulting in poor recommendation effect.

In view of the problems existing in the above system, this paper designs the intelligent function of the vocational education system under the mobile learning mode, tests the intelligent function of the system, verifies the effectiveness and timeliness of the system designed in this paper, improves the intelligence and personalization of the vocational education teaching system, and lays a good foundation for the improvement of students' academic performance.

\section{Mobile Learning Mode}

Information technology and Internet technologies are combined in the mobile learning mode. It is an e-learningbased informal distant learning style. Learners' learning is more convenient and ways are more diverse when a digital multiterminal all media learning platform is established [9]. All learners may log in, view, and download a vast variety of learning materials, whether they are using mobile phones, tablets, PCs, or other terminal devices.

The mobile learning mode builds an information service system serving open education and lifelong education through the system construction of a portal platform and three centers. The structural framework of the mobile learning platform is shown in Figure 1.

In the structure of mobile learning platform, the server needs to build five server clusters: basic platform server cluster, application server cluster, data storage server cluster, data exchange server cluster, and basic application network and security. Three simulation warehouses are established: user data warehouse, application data warehouse, and resource data warehouse [10].

\section{Design of Intelligent Function Module of Vocational Education System under Mobile Learning Mode}

3.1. System Intelligent Function Architecture. Combined with the mobile learning mode, the intelligent functional architecture of vocational education system is designed, as shown in Figure 2.

The whole vocational education system is logically divided into five layers: customer operation end, logic verification, business logic, data interface, and data resource layer. In the mobile learning mode, the first three layers can be regarded as the function realization of the mobile client, and the last two layers can be regarded as the server-side function [11].

3.2. Design of Registration Function Module. In order to strengthen the management of the mobile learning platform of the vocational education system, learners need to register and establish a personal account before logging in. Before logging in to the learning platform for learning each time, they need to enter personal account, password, and other information. After background verification, if the verification is successful, they can perform specific operations on the platform according to the permissions given by the system [12]. After successful login, the user information is saved in the session. The specific process is as follows:

(i) Log in to the interface of vocational education system and enter user name and password

(ii) Learners click Submit, and the entered user name and password are encapsulated into JSON format, encrypted with 3DES algorithm, and submitted to the web server

(iii) The web server decrypts 3DES and restores the data in JSON format and then parses the JSON data to obtain the user name and password

(iv) Verify the entered user name and password, and process the verification results accordingly

(v) If the user exists in the database server and is legal, the result is returned to the web server [13]

(vi) The web server returns encrypted JSON format data to the mobile client

(vii) Decrypt according to the returned result, obtain the original data, and initialize according to the returned result

(viii) The mobile client prompts that the login is successful, so as to obtain the corresponding operation permission [14]

3.3. Course Learning Function Module Design. The course learning function is divided into my course, popular course, course evaluation, and other specific functions. The details are as follows.

3.3.1. My Course. After successful login, each user has a dedicated personal learning space to record their learning status, learning progress, and relevant course selection 


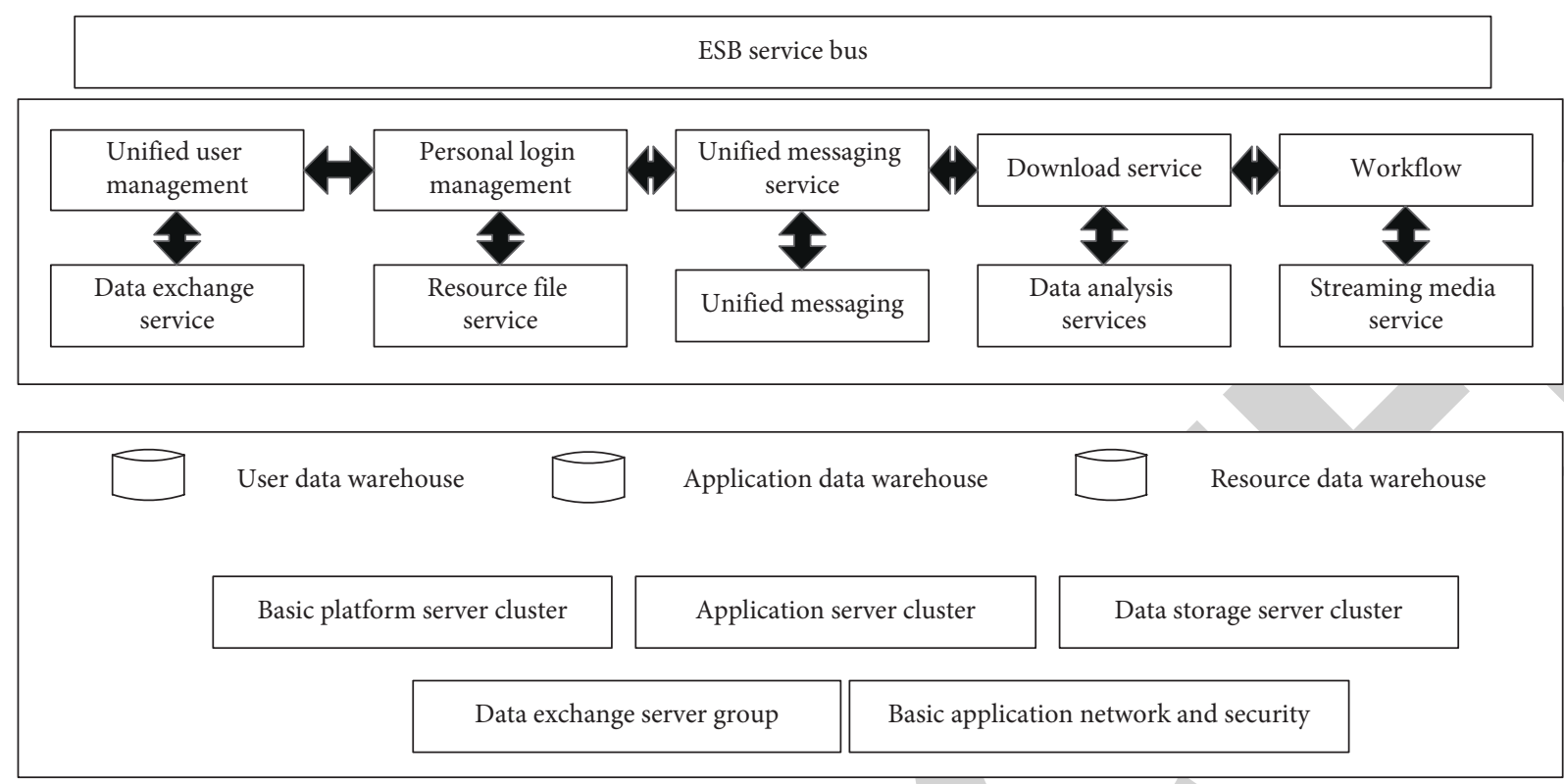

FIGURE 1: Structural framework of mobile learning platform.

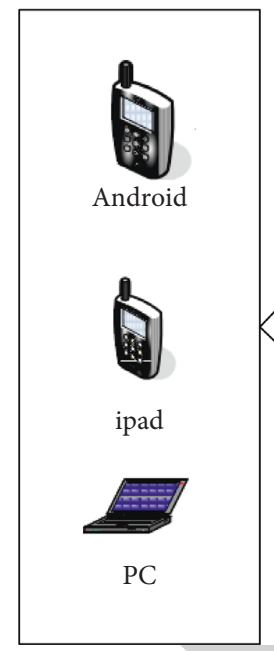

Customer operating terminal

\section{Figune 1: Structural framework of mobile learning platform.}
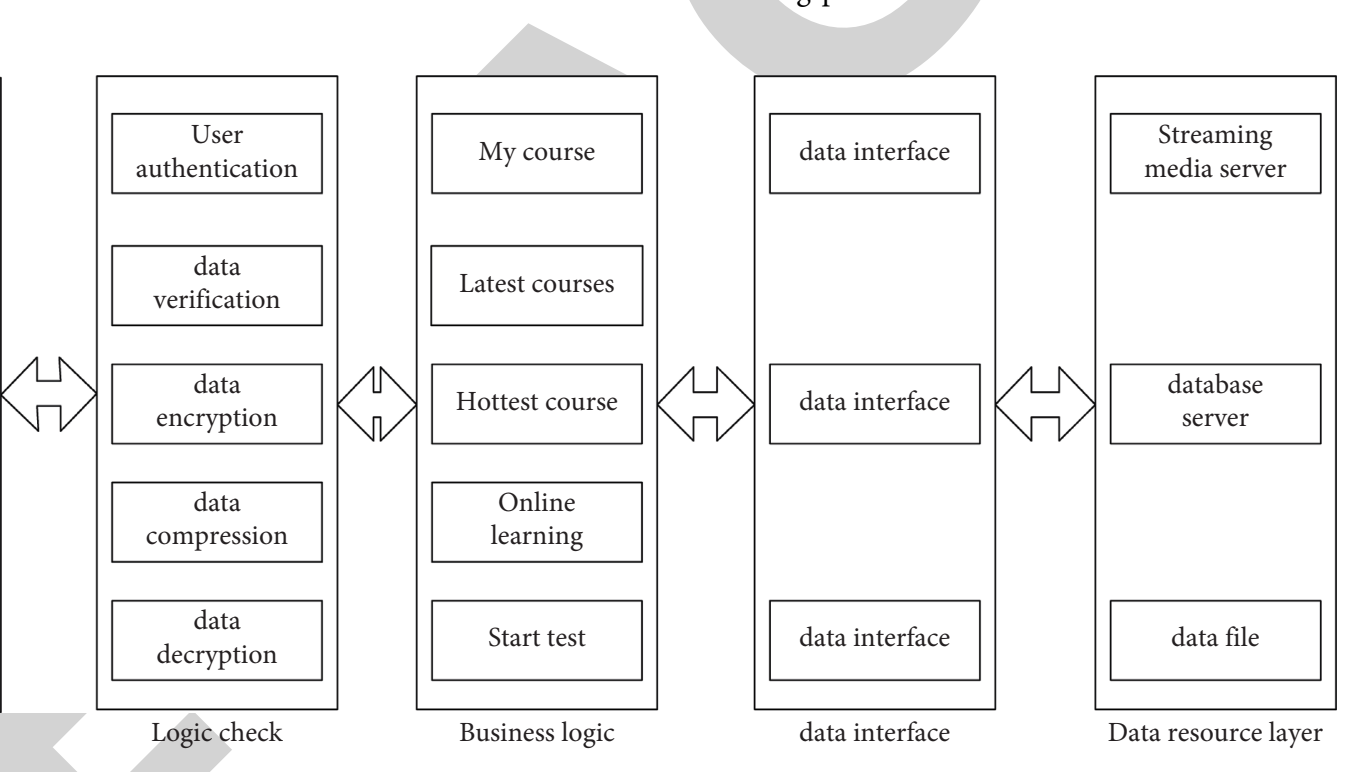

FIGURE 2: Intelligent functional architecture of vocational education system.

results [15]. Users can query the course selection list in "my courses" to record the courses they are interested in. Here, you need to query the associated vocational education course information in the database according to the user ID and site ID. The specific process is as follows:

(i) On the premise of successful login, the user clicks the "my course" button [16].

(ii) After the client listens to the user's click behavior, it will call the "my course" query interface through HTTP post.

(iii) The web server decrypts and deserializes JSON format data to find out whether there is user login information in the session. (iv) The web server queries the database for its associated course information according to the user ID and site ID in the session. There may be no or multiple courses [17].

(v) The database returns the course list records according to the query results.

(vi) The web server encapsulates the data into JSON format according to the course list and encrypts it with 3DES.

(vii) The web server returns the encrypted information of my course to the mobile client.

(viii) The mobile client decrypts the data according to the specific format, reads the JSON format data, and initializes the course list. 
(ix) The mobile client presents the "my courses" list data in a specific layout and style [18].

3.3.2. Ranking of Popular Courses. Popular courses are vocational education courses with high learning frequency. The more people learn, the higher the ranking, which represents the quality of the course to a certain extent. The specific work flow is as follows:

(i) On the premise of successful login, the user clicks the "popular course ranking" button.

(ii) After the client listens to the user's click behavior, it will call the click ranking query interface through HTTP post.

(iii) The web server decrypts and deserializes JSON format data to find out whether there is user login information in the session [19].

(iv) The web server queries the course information in the database according to the user ID and sorts it in descending order according to the number of clicks; that is, the more popular the course is, the higher it is.

(v) The database returns the course list record.

(vi) The web server assembles JSON format data according to the course list and encrypts it with 3DES.

(vii) The web server returns the encrypted information of the click ranking course to the mobile client [20].

(viii) The mobile client decrypts the data, submits JSON format data, and initializes the ranking list.

(ix) The mobile client displays the list of popular courses to users according to specific layout and style.

3.3.3. Curriculum Evaluation. Mobile terminal users can evaluate the selected courses or courses they study. According to the system regulations, each learner can only evaluate each course once and cannot evaluate it again. The specific process is as follows:

(i) On the premise of successful login, the user clicks "course evaluation"

(ii) After listening to the user's click behavior, the client assembles JSON format data, calls the evaluation interface, and submits the serialized byte stream through HTTP post [21]

(iii) The web server decrypts and deserializes JSON format data to find out whether there is user login information in the session

(iv) The web server adds an evaluation in the evaluation data table according to the evaluation level submitted by the user, user ID, and course ID

(v) The database returned a successful insert

(vi) The web server queries the evaluation table to calculate the average value of the evaluation of this course (vii) The database server returns the average value of the evaluation

(viii) The web server encapsulates JSON format data according to the course list, adds the average value of the course evaluation, and encrypts it with $3 \mathrm{DES}$

(ix) The web server encapsulates the JSON format data, serializes it, encrypts it, and returns it to the mobile client

(x) The mobile client decrypts the data and submits JSON format data [22]

(xi) The client prompts the user that the evaluation is successful

3.4. Design of Examination and Evaluation Function Module. The function of examination and evaluation is to test the course learning module. The specific interaction is shown in Figure 3.

The specific interaction process is as follows:

(i) Learners enter the examination and evaluation interface and select the evaluation method according to the actual needs.

(ii) The test evaluation interface sends a request to the server, and the server reads the test questions from the database according to the user's request and returns to the test evaluation interface.

(iii) The learner carries out the answer test. After all the questions are answered, the test completion request is submitted to the server. After receiving the learner's request, the server checks the answers according to the extracted questions and generates the evaluation results [23].

(iv) Of course, learners can view the evaluation results or send multiple evaluation results to the server. The server makes comprehensive statistics according to learners' previous answers and responds to the evaluation data statistics report to learners.

3.5. Design of Communication and Interaction Function Module. Communication and interaction are grouped according to learners' interests. Learners can apply for adding groups according to their personal interests or create groups as managers. Members of the group can publish relevant topics or activities, share, and grow together. The specific interaction process is shown in Figure 4.

The whole interaction process is as follows:

(1) Learners may use the interactive interface to look at information such as hot groups, recent themes, and recent actions. If the user picks a popular group in this interface, it will submit a request to the server.

(2) The server handles the request after receiving the command. If it needs to read data from the database, it will make a request to do so [24].

(3) The database replies to the server by retrieving relevant data in response to the server's request. 


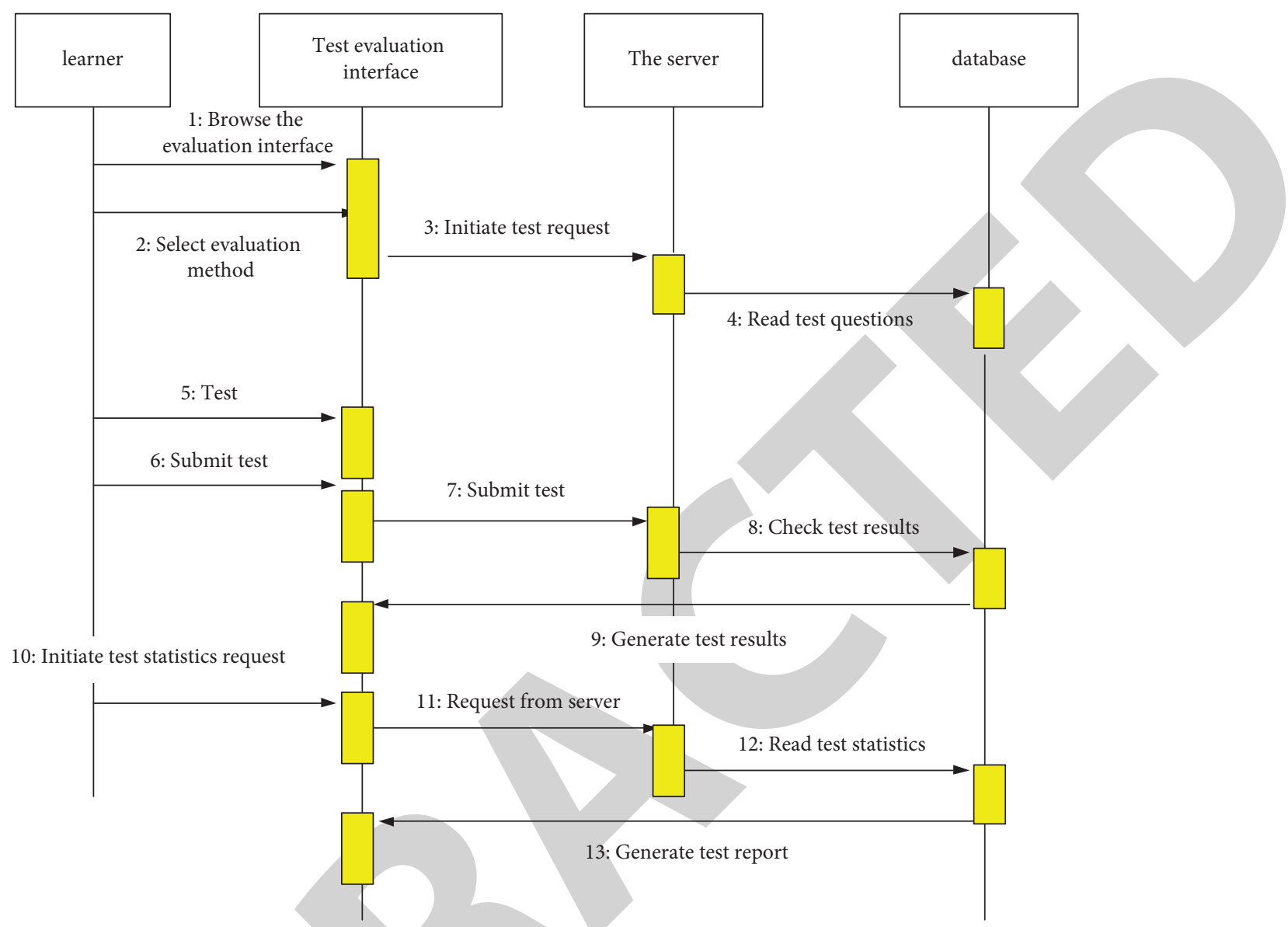

FIgURE 3: Interaction flow of test module.

(4) The server wraps the data and delivers it in a certain manner in the interactive interface after receiving it. provide them with a selection of different resources and assessment levels from which they may pick according to their preferences $[26,27]$.
3.6. Design of Mobile Learning Function Module. The mobile learning module enables students to find learning materials online through mobile terminals, including text, pictures, audio, video, and other forms of resources and can obtain the required materials at any time. You can also customize and obtain relevant learning services through SMS [25]. In addition, learners can also connect to the resource server through the Internet and upload their own resources. The module provides two learning modes, one is live (on-demand) learning and the other is autonomous learning, and also provides a word query service, as shown in Figure 5.

(1) Upload the whole process of the teacher's course explanation in the form of video to the mobile terminal and categorize it according to the course topic so that students may study on-demand.

(2) Students may study on their own by accessing the learning information they need. If students choose synchronous learning as their learning style, the system will automatically supply them with the following sorts of learning materials for each class, based on their learning progress and teaching goals. If students opt to explore freely, the system will
3.7. Design of Personalized Recommendation Function Module. For the subject distribution of vocational education resources, $A=\left\{A_{1}, A_{2}, \ldots, A_{T}\right\}$ is defined to represent the subject set of vocational education resources. For a vocational education resource $l$, the posterior probability is $p\left(A_{i} \mid l\right)$. Therefore, the main part vector of vocational education resources composed of posterior probability is $\left(p\left(A_{1} \mid l\right), p\left(A_{2} \mid l\right), \ldots, p\left(A_{T} \mid l\right)\right)$, and $L$ represents the number of subject sets of vocational education resources. For the user's interest orientation, suppose that $l$ represents the set of vocational education resources published by the user and then the $L$-dimensional vector $\left(w_{1}, w_{2}, \ldots, w_{L}\right)$ represents the user's interest orientation in vocational education resources, and the calculation formula is

$$
w_{i}=\sum_{j=1}^{d} p\left(A_{i} \mid l_{j}\right) .
$$

According to the user's interest weight, $w_{i}$ is improved by personalized adaptive learning, and the following result is obtained: 


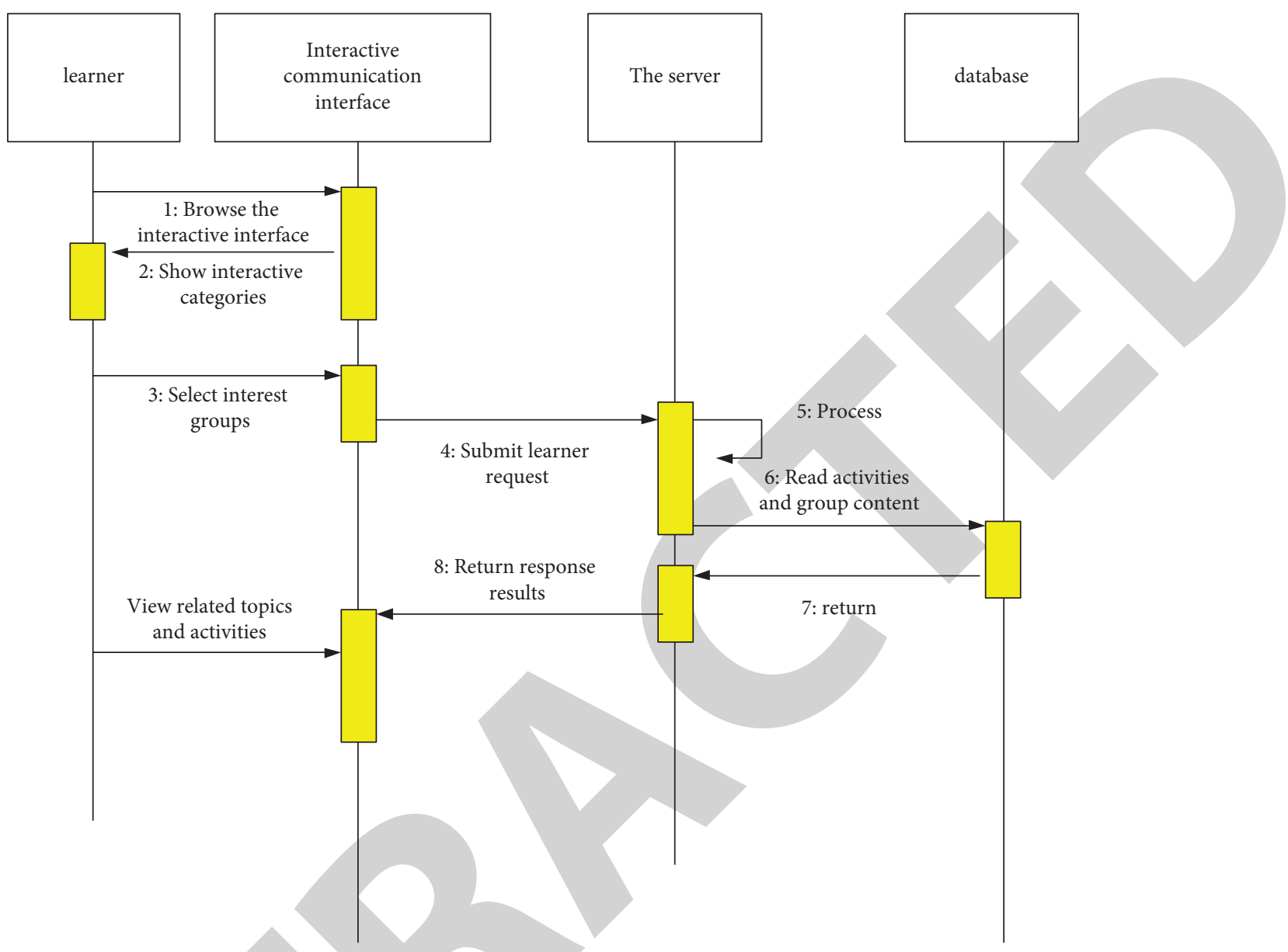

FiguRE 4: Sequence diagram of communication and interaction module.

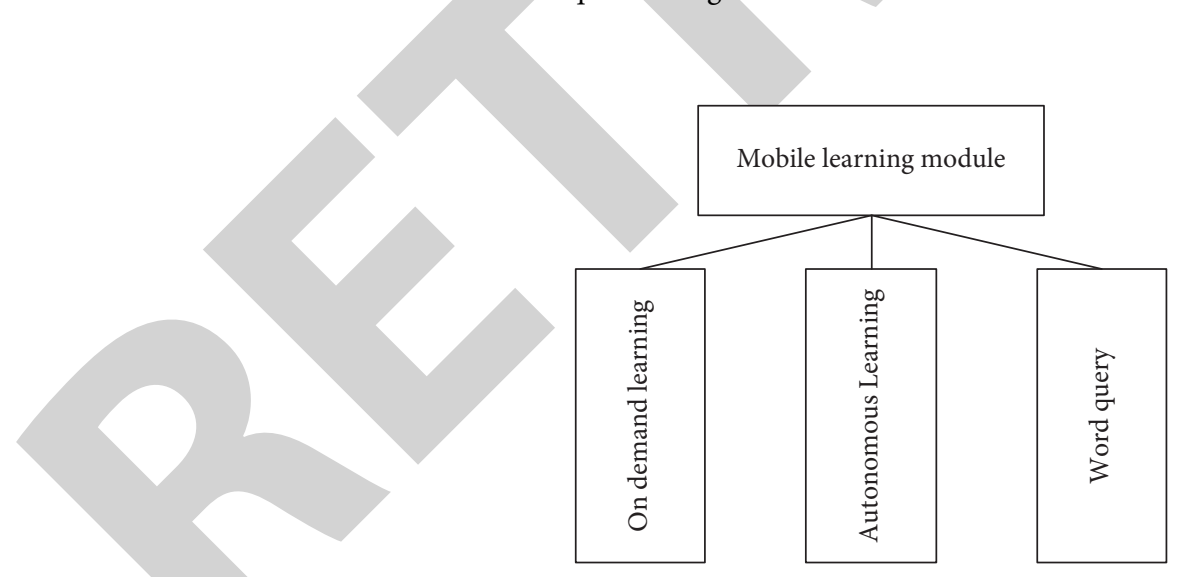

Figure 5: Mobile learning module.

$$
w_{i}=\sum_{j=1}^{d} s_{j} p\left(A_{i} \mid t_{j}\right),
$$

where $s_{j}$ represents the user's interest weight value in vocational education resources, which can reflect the user's preference set for vocational education resources. The greater the value of $s_{j}$, the higher the user's preference for vocational education resources.

Assuming that the vocational education resource $l$ is composed of $n$ words, the $n$ word is marked as $w_{n}$, and the subject of $w_{n}$ is defined as $z_{w_{n}}$, and then the probability of $z_{w_{n}}$ is calculated as

$$
P\left(z_{u_{i}}=j \mid Z_{t, i}, l, \varphi, s\right) \propto \frac{P\left(z_{w_{i}}=j, Z_{t, i}, l \mid \varphi, s\right)}{P\left(Z_{t, i}, l \mid \varphi, s\right)} .
$$

On the basis of formula (3), if the subject distribution of word $v_{n}$ is $W_{v_{n}}=\left(w_{1}, w_{2}, \ldots, w_{T}\right)$, then the standardization probability of $w_{i}$ is 
TABle 1: Test environment.

\begin{tabular}{lcc}
\hline Testing environment & To configure & Parameter \\
\hline Hardware environment & CPU & Pentium Quad Processor \\
Software environment & Memory capacity & 2 G \\
Testing environment & Hard disk capacity & $250 \mathrm{G}$ \\
Hardware environment & Graphics card & Intel integrated graphics card \\
Software environment & Operating system & Windows XP SP2 \\
\hline
\end{tabular}

$$
v_{j}=\frac{P\left(z_{x_{i}}=j \mid Z_{t, i}, l, \varphi, s\right)}{\sum_{j=1}^{L} P\left(z_{u_{i}}=j \mid Z_{t, i}, l, \varphi, s\right)} .
$$

The probability that vocational education resource $l$ belongs to topic $j$ is

$$
\theta_{t, j}=\frac{n(j, l)+s}{n(l)+L s} .
$$

According to $\theta_{t, j}$, the average preference similarity of users in $R$ cycles can be defined:

$$
\operatorname{sim}_{R}=\frac{\sum_{(1 / 2)}^{R} \operatorname{sim}\left(u_{k-1}, u_{k}\right)}{R-1} .
$$

In order to facilitate comparison, the user's average preference similarity can be personalized adaptive learning to calculate the user's preference similarity:

$$
\operatorname{sim}\left(U_{k-1}, U_{k}\right)=\cos \theta=\frac{\overrightarrow{u_{k-1} \cdot \overrightarrow{u_{k}}}}{\left|\mu_{k-1}\right| \cdot\left|\mu_{k}\right| \mid} .
$$

\section{Simulation Experiment Analysis}

In order to verify the effectiveness of the intelligent function of vocational education system in practical application under the mobile learning mode designed in this paper, a simulation test is carried out. The test environment is shown in Table 1.

In the test environment, the network architecture of vocational education system under the mobile learning mode is built, as shown in Figure 6 .

Under the above background, the registration and login function module, course learning function module, and examination and evaluation function module are selected for testing.

\subsection{Registration and Login Function Module Test}

Purpose: to verify whether the module operates according to normal business logic

Test content: whether the user can log in normally

Test results are shown in Table 2.

The test contents and results are shown in Table 3.
4.2. Course Learning Function Module Test. Objective: to verify whether the module displays, plays, and evaluates courses normally.

4.3. Test and Evaluation Function Module Test. Objective: to verify whether the module displays, plays, and evaluates courses normally.

The test contents and results are shown in Table 4.

According to Tables 2-4, the intelligent function of vocational education system under the mobile learning mode designed in this paper can operate normally and the system performance is good.

In order to further verify the effectiveness of the system in this paper, the vocational education system under the mobile learning mode designed in this paper, the vocational education auxiliary teaching system based on data mining designed in literature [28], and the vocational education distance teaching auxiliary system based on facial feature recognition designed in literature [29] are used to compare and analyze the running time of intelligent functions. The comparison results are shown in Table 5.

According to Table 5, the running time of the intelligent function of the vocational education system under the mobile learning mode designed in this paper is within $15.0 \mathrm{~s}$, and the running time of the intelligent function of the vocational education auxiliary teaching system based on data mining designed in literature [30] is within $38.9 \mathrm{~s}$; in literature [31], the running time of the intelligent function of the distance teaching auxiliary system of vocational education based on facial feature recognition is within $28.9 \mathrm{~s}$. Under the mobile learning mode designed in this paper, the running time of the intelligent function of the vocational education system is short and the operation efficiency is high.

In order to further verify the effectiveness of this system, the vocational education system, literature [32] system, and literature system under the mobile learning mode designed in this paper are used to recommend vocational education resources and test the recommendation accuracy of the three systems. The test results are shown in Figure 7.

According to Figure 7, under the mobile learning mode designed in this paper, the accuracy of Vocational Education Resource Recommendation by vocational education system can reach 100\%, the accuracy of Vocational Education 


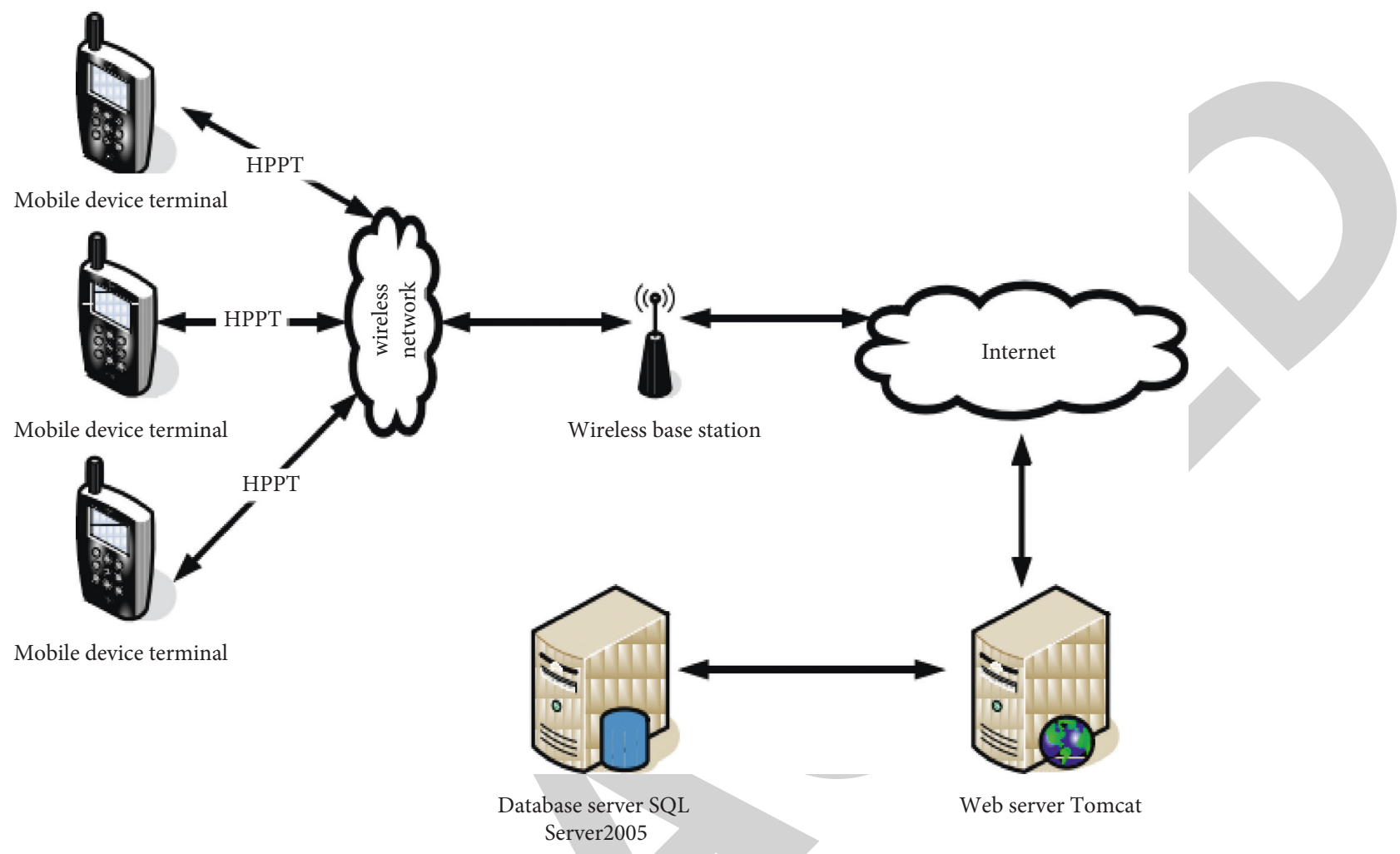

FIGURE 6: Network architecture of vocational education system under mobile learning mode.

TABLE 2: Function test results of registration and login function module.

Use case

Enter the wrong user name, password, and verification code Close the client's network connection

Shut down the server

The information input is accurate and the network connection is normal

\section{Test result}

Please enter ID, password, and verification code Remind that the ID, password, and verification code entered are incorrect

Please check the system network connection Connection timeout, server-side exception, please contact the administrator

Successfully enter the system main interface

TABLE 3: Function test results of course learning function module.

\begin{tabular}{|c|c|c|}
\hline Test content & Expected judgment & Test result \\
\hline Teaching online broadcast & Can I play it online & Video and audio can be played online and according to the learning records \\
\hline Teaching course download & $\begin{array}{l}\text { Can I download the } \\
\text { courseware }\end{array}$ & $\begin{array}{l}\text { Video and audio files can be downloaded. The default storage address is } \\
\text { memory card }\end{array}$ \\
\hline $\begin{array}{l}\text { Teaching curriculum } \\
\text { evaluation }\end{array}$ & Can I evaluate the course & Word limit should be set for evaluable courses \\
\hline
\end{tabular}

TABle 4: Function test results of test evaluation function module.

\begin{tabular}{|c|c|c|}
\hline Test content & Expected judgment & Test result \\
\hline $\begin{array}{l}\text { Basic question type } \\
\text { training }\end{array}$ & $\begin{array}{l}\text { Is the question type displayed according to } \\
\text { the specialty }\end{array}$ & $\begin{array}{l}\text { Initialize the question bank and display the question type according } \\
\text { to the selected course }\end{array}$ \\
\hline Timing function & Can I time it & The test timing function is enabled, in seconds \\
\hline Scori & Can you score & Enter the test scoring function to score in real time \\
\hline Collectio & Can I collect topics & Click collect to successfully collect the question \\
\hline Collection & Can I collect wrong questions & Answer matching error automatic collection of wrong questions \\
\hline
\end{tabular}


TABLE 5: Comparison results of intelligent function running time (s).

\begin{tabular}{lccc}
\hline Number of experiments/time & Literature [6] system & Literature [7] system & Paper system \\
\hline 10 & 32.5 & 21.2 & 11.2 \\
20 & 33.6 & 22.2 & 11.5 \\
30 & 34.5 & 23.1 & 1.6 \\
40 & 34.9 & 23.8 & 12.5 \\
50 & 35.1 & 24.5 & 12.9 \\
60 & 36.5 & 25.0 & 13.4 \\
70 & 36.9 & 25.4 & 13.5 \\
80 & 37.0 & 26.7 & 14.0 \\
90 & 37.2 & 27.2 & 14.5 \\
100 & 38.9 & 28.9 & 15.0 \\
\hline
\end{tabular}

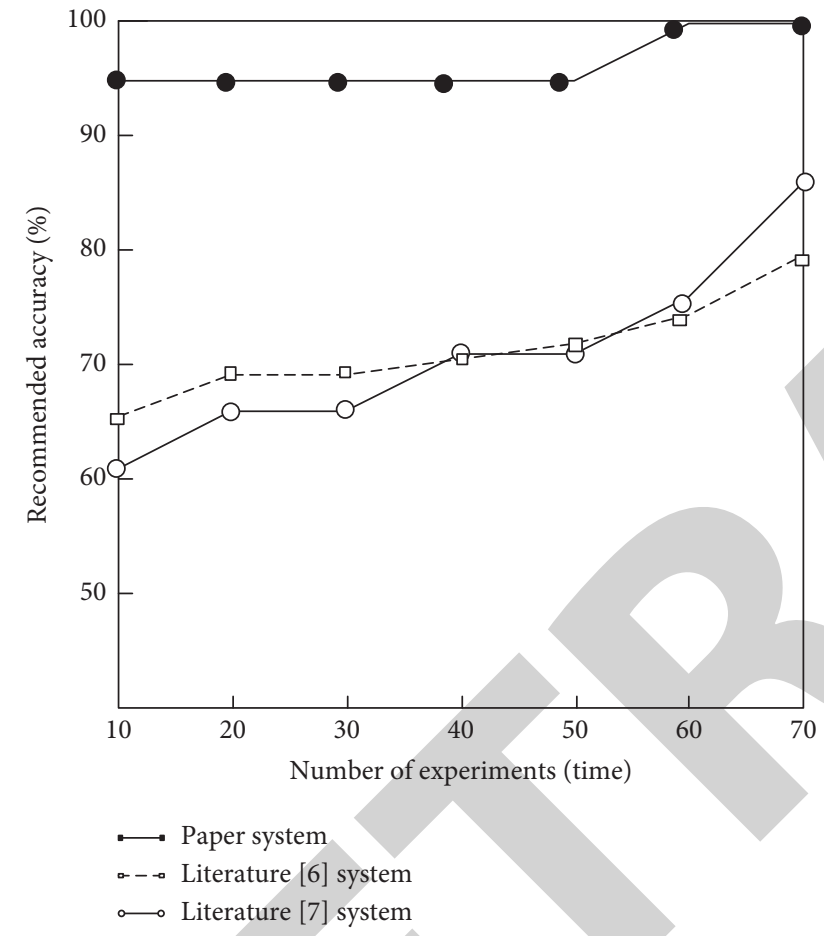

Figure 7: Comparison results of Vocational Education Resource Recommendation accuracy of three systems.

Resource Recommendation by literature [33] system is only $80 \%$, and the accuracy of Vocational Education Resource Recommendation by literature [34] system is only $85 \%$. Under the mobile learning mode, the vocational education system designed in this paper has the highest accuracy and the best recommendation effect.

\section{Conclusion}

In view of the low efficiency of the intelligent function of the traditional vocational education system and the poor effect of Vocational Education Resource Recommendation, in the mobile learning mode, through the registration and login function module, course learning function module, examination and evaluation function module, communication and interaction function module, mobile learning function module, and personalized recommendation function module, a new vocational education system is designed.
Through the personalized recommendation function module, the user's interest weight is calculated by using personalized adaptive learning to obtain the interest weight value of vocational education resources, and the personalized recommendation of vocational education resources is carried out according to the interest weight value. Finally, through the simulation test, the running time of the intelligent function of the vocational education system under the mobile learning mode designed in this paper is within $15.0 \mathrm{~s}$, and the recommendation accuracy of vocational education resources is up to $100 \%$. It is verified that the operation efficiency of this system is high and the recommendation effect of vocational education resources is good.

\section{Data Availability}

The data used to support the findings of this study are included within the article.

\section{Conflicts of Interest}

The author declares that there are no conflicts of interest.

\section{References}

[1] S. Cheng, X. Zhao, and W. Li, "Design and implementation of college teaching assistant system based on bmob back-end cloud," Computer Programming Skills and Maintenance, vol. 397, no. 7, pp. 109-113, 2018.

[2] X. Liang, "Design of higher mathematics assistant teaching system based on data mining," Higher Science Rducation, vol. 5, pp. 38-43, 2019.

[3] R. Wang and C. Jiang, "Design of the intelligent education system based on the piano introduction," International English Education Research: English Version, vol. 2, pp. 3-7, 2019.

[4] W. Gong, L. Tong, W. Huang, and S. Wang, "The optimization of intelligent long-distance multimedia sports teaching system for IOT," Cognitive Systems Research, vol. 52, pp. 678-684, 2018.

[5] X. Jiang, "Computer aided teaching system based on wechat public platform," Modern Scientific Instruments, vol. 3, pp. 44-49, 2020.

[6] J. Zhou, "Design of computer aided classroom teaching system based on data mining," Modern Electronic Technology, vol. 43, no. 2, p. 3, 2020.

[7] H. Liu, Q. Zhu, and T. sun, "Distance teaching assistant system based on facial feature recognition," Software Engineering and Application, vol. 10, no. 2, p. 8, 2021. 
[8] Y. J. Zhuoma and H. Zhang, "Design and implementation of field geology teaching assistant system based on android," Geological Education in China, vol. 28, no. 3, pp. 92-96, 2019.

[9] Y. Han, H. Yao, and F. Zhou, "Research on the intelligent ecology of modern vocational education system," Modern Educational Technology, vol. 28, no. 1, pp. 114-120, 2018.

[10] S. Sevgican, M. Turan, K. Gokarslan, H. B. Yilmaz, and T. Tugcu, "Intelligent network data analytics function in 5G cellular networks using machine learning," Journal of Communications and Networks, vol. 22, no. 3, pp. 269-280, 2020.

[11] I. V'atibuick, A. Kurban, and H. Ziyu, "Research on Chinese auxiliary teaching system in deaf mute school," Computer Engineering and Application, vol. 34, pp. 225-229, 2020.

[12] S. Zheng, F. Wang, and J. Su, "Design of college physics teaching assistant system based on MATLAB," Educational Modernization, vol. 6, no. 87, pp. 228-254, 2019.

[13] G. Hong, "Design and implementation of college students' extracurricular learning assistant system based on MVC," Modern Vocational Education, vol. 12, no. 1, pp. 76-77, 2018.

[14] Y. Ren, X. Li, and X. Zheng, "Discussion on the integrated teaching of theory and practice of driving assistance system design based on the integration of collaborative education and PBL," Educational Modernization, vol. 6, no. 70, pp. 148-156, 2019.

[15] Y. Zhang, S. Xin, and W. Dong, "Design and implementation of teaching assistant system based on wechat interface," Science and Technology Innovation Guide, vol. 15, no. 15, pp. 3-11, 2018.

[16] X. Li and D. Wang, "Design and research of teaching assistant system based on single chip microcomputer," Digital World, vol. 8, pp. 2-8, 2018.

[17] Y. Zhang, "Computer aided instruction system based on web database technology," Journal of Suzhou Institute of Education, vol. 21, no. 2, pp. 123-125, 2018.

[18] J. Li, "Auxiliary teaching system based on python," Electronic Technology and Software Engineering, vol. 163, no. 17, pp. 67-68, 2019.

[19] C. Liu, Y. Xue, and M. Li, "Design of assistant teaching system based on intelligent analysis of learning behavior data," Journal of Tianjin Radio and TV University, vol. 23, no. 2, pp. 21-25, 2019.

[20] S. Chen, W. Zhou, and J. Wang, "Intelligent computer aided instruction system for clinical medicine specialty," Higher Medical Education in China, vol. 8, no. 6, pp. 11-12, 2018.

[21] Z. Zhao and P. Jiang, "Design of interest oriented multimedia teaching assistant system," Electronic Technology and Software Engineering, vol. 11, no. 2, p. 122, 2019.

[22] S. Zhao, "Optimization design and analysis of art assisted curriculum system under wechat platform," Microcomputer Application, vol. 34, no. 4, pp. 20-22, 2018.

[23] J. Wang, "Design and implementation of distance multimedia teaching courseware," Microcomputer Application, vol. 35, no. 2, pp. 93-95, 2019.

[24] X. Wang, "Design and implementation of education and teaching research management information system based on web," Chinese Journal of Multimedia and Network Teaching, vol. 9, pp. 58-59, 2018.

[25] J. Li, "Multimedia classroom cloud management system based on network central control," Electronic World, vol. 568, no. 10, pp. 69-70, 2019.

[26] M. Talha, M. Sohail, R. Tariq, and M. T. Ahmad, "Impact of oil prices, energy consumption and economic growth on the inflation rate in Malaysia," Cuadernos de Economía, vol. 44, no. 124 , pp. 26-32, 2021.
[27] M. Talha, S. Azeem, M. Sohail, A. Javed, and R. Tariq, "Mediating effects of reflexivity of top management team between team processes and decision performance," Azerbaijan Journal of Educational Studies, vol. 1, no. 1, pp. 105$119,2020$.

[28] M. Talha, M. Sohail, and H. Hajji, "Analysis of research on amazon AWS cloud computing seller data security," International Journal of Research in Engineering Innovation, vol. 4, no. 3, pp. 131-136, 2020.

[29] M. Talha, "Financial statement analysis of atlas honda motors, indus motors and pak suzuki motors (evidence from Pakistan)," Ilköğretim Online, vol. 20, no. 4, 2021.

[30] M. Talha, R. Tariq, M. Sohail, A. Tariq, A. Zia, and M. Zia, "Review of international geographical education ISO 9000: (1987-2016) a trend's review," Review of International Geographical Education Online, vol. 10, 2020.

[31] M. Talha, "A history of development in brain chips in present and future," International Journal of Psychosocial Rehabilitation, vol. 24, no. 2, 2020.

[32] Y. Zhao and M. Talha, "Evaluation of food safety problems based on the fuzzy comprehensive analysis method," Food Science Technology, 2021.

[33] Z. Yang and M. Talha, "A coordinated and optimized mechanism of artificial intelligence for student management by college counselors based on big data," Computational and Mathematical Methods in Medicine, vol. 2021, Article ID 1725490, 11 pages, 2021.

[34] J. Chen and M. Talha, "Audit data analysis and application based on correlation analysis algorithm," Computational and Mathematical Methods in Medicine, vol. 2021, Article ID 2059432, 11 pages, 2021. 